\title{
Applications of Terrestrial Laser Scanning (TLS) in Mining: A Review
}

\author{
Bilgehan Kekeç$^{* 1}$, Niyazi Bilim ${ }^{1}$, Emre Karakaya ${ }^{1}$, , Dhikra Ghiloufi ${ }^{1}$ \\ ${ }^{1}$ Konya Technical University, Faculty of Engineering and Department of Natural Sciences Mining Engineering, Konya, Turkey
}

\section{Keywords}

Terrestial laser scanning LIDAR

Mining

3D

Measurement

\begin{abstract}
This study investigates in depth Terrestrial Laser Scanning technology (TLS), its working and measurement principle, 3D Terrestrial Laser Scanning softwares and the advantages of this scanning method. This paper also stresses the advantages of adopting this technology in quarries and mines and provides examples of researches that have demonstrated the superiority of TLS systems over the traditional scanning methods in terms of practicability, reliability and accuracy in numerous mining engineering applications such as deformation measurements, rock fall and landslide control, volume calculations and detection of discontinuities.
\end{abstract}

\section{INTRODUCTION}

Airborne Laser Scanning (ALS) and Terrestrial Laser Scanning (TLS) technologies were developed in the 1970s. The core of these technologies is based on the LIDAR (LIGHT Detection and Ranging) technique which enables emitting laser pulses to the studied surface or object and measuring the time required by the reflected waves to reach back the laser sensors allowing to measure the distance between the TLS device and the object/surface. This technology was adopted as a reflectorless distance measurement method in geodetic instruments in the 1990s after the development of the first total station (TS) without a reflector at Ruhr University in Germany in 1994 (Reshetyuk, 2006; Scherer, 2004). The end of the 1990s marked the commercial launch of Terrestrial Laser Scanners (TLS) as their performance, functionality and efficiency substantially improved.

TLS technology enables acquiring 3-dimensional (3D) point information much faster than traditional measurement techniques. The obtained set of data points are defined as "point clouds". Combining, saving and deleting unnecessary point clouds allows creating 3D models of different objects (Karasaka \& Beg, 2021). Geodesic and photogrammetry methods are less effective than the TLS method in terms of accuracy, speed and efficiency in conducting the necessary calculations during the measurement process (Engin \& Maerz, 2016).

Today, on account of its reliability, accuracy and efficiency, TLS technology has become an efficient tool in numerous applications. The usage areas of this technique keep expanding as it has been proven to be a more advantageous than the traditional methods in terms of operability, reliability and time and cost efficiency. Numerous softwares can be utilized for the interpretation of TLS data for the purpose of conducting measurement calculations and modeling objects of different sizes and geometries. Terrestrial laser scanners are commonly used in numerous engineering applications such as cross sectional area and volume calculations, monitoring and measurement of deformations, historical artifacts documentation studies and creating 3D city models (Karasaka \& Beg, 2021).

\section{METHOD}

\section{Measurement Principle of Terrestrial Laser Scanners}

Terrestrial laser scanners allow determining with high accuracy the time elapsed between sending a laser beam to the surface/object to be studied and the return of the transmitted laser beam (Figure 1). Equation (1) enables calculating the distance between the measured surface and the TLS device (Özdoğan et al., 2018; Engin \& Maerz., 2016).

$$
\mathrm{D}=\mathrm{c} \times \mathrm{t} / 2
$$

$\mathrm{D}=$ Distance between the TLS device and the measured surface $(\mathrm{m})$

$\mathrm{c}=$ Speed of light $(299792458 \mathrm{~m} / \mathrm{s})$

$\mathrm{t}=$ Time taken by the emitted light beam to reach the studied surface, reflect back from it and return to the laser sensor placed on the device (s). 


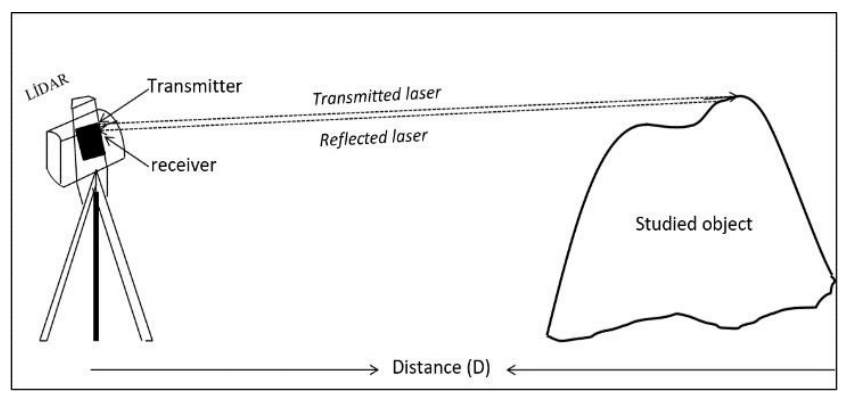

Figure 1. The measurement principle of LIDAR technology

The measurement principle of electronic tachometers and terrestrial laser scanners show strong similarities (Boehler \& Marbs, 2002). These devices allow acquiring accurate and precise measurements for long distances (Fröhlich \& Mettenleiter, 2004; Karşıdağ, 2011). Figure 2 highlights the equipment used with TLS systems.

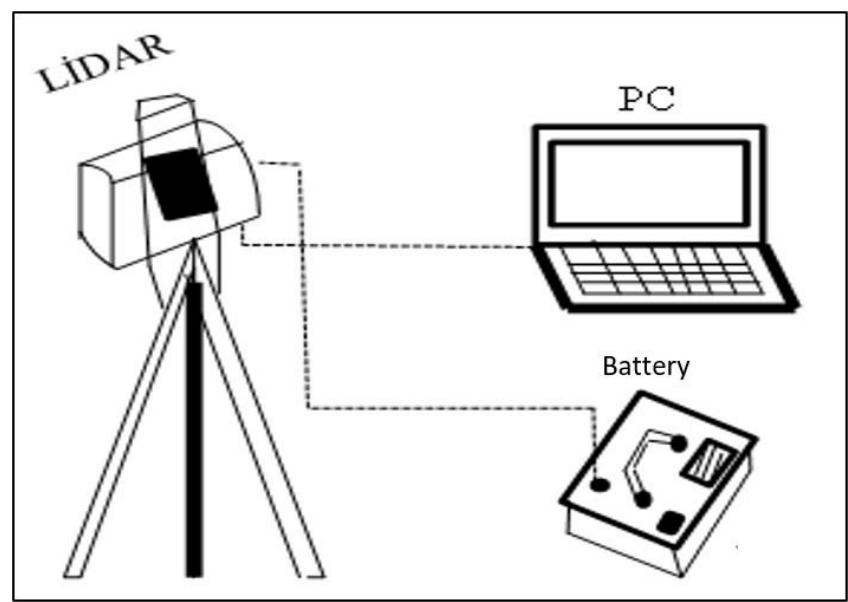

Figure 2. The equipment used with TLS systems

\section{Working Principle of Terrestrial Laser Scanners}

The terrestrial laser scanner has both a horizontal and a vertical axis laser beam emission mechanism. The laser beam emitted from the electronic unit of the terrestrial laser scanner hits the optical unit located on the body of the TLS device and reflects from the optical unit at a certain angle with the horizontal to beam toward the studied surface. As the terrestrial laser scanner emits laser beam and receives data, it rotates at a very small angle around its vertical axis along the line to be scanned. This process continues until the screening process is complete (Kraus, 2004; Özdoğan, 2015).

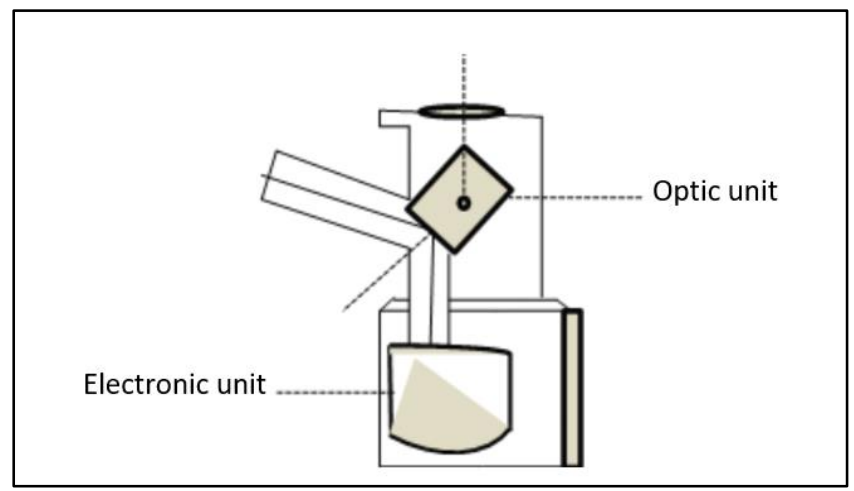

Figure 3. The working principle of the TLS device
A point cloud data is obtained at the end of each scanning process. Each laser point in this point cloud is recorded by the terrestrial laser scanner using its polar coordinates $(\mathrm{r}, \varphi, \theta)$. The Cartesian coordinates $(\mathrm{x}, \mathrm{y}, \mathrm{z})$ of these points expressed in polar coordinates are determined using the software of the scanner. Besides the polar coordinates of each laser point, the scanner also records the density of the energy that hits the object and reflects back from it (Slob et al., 2004; Özdoğan \& Deliormanl, 2018). Figure 4 demonstrates the working principle of the TLS device.

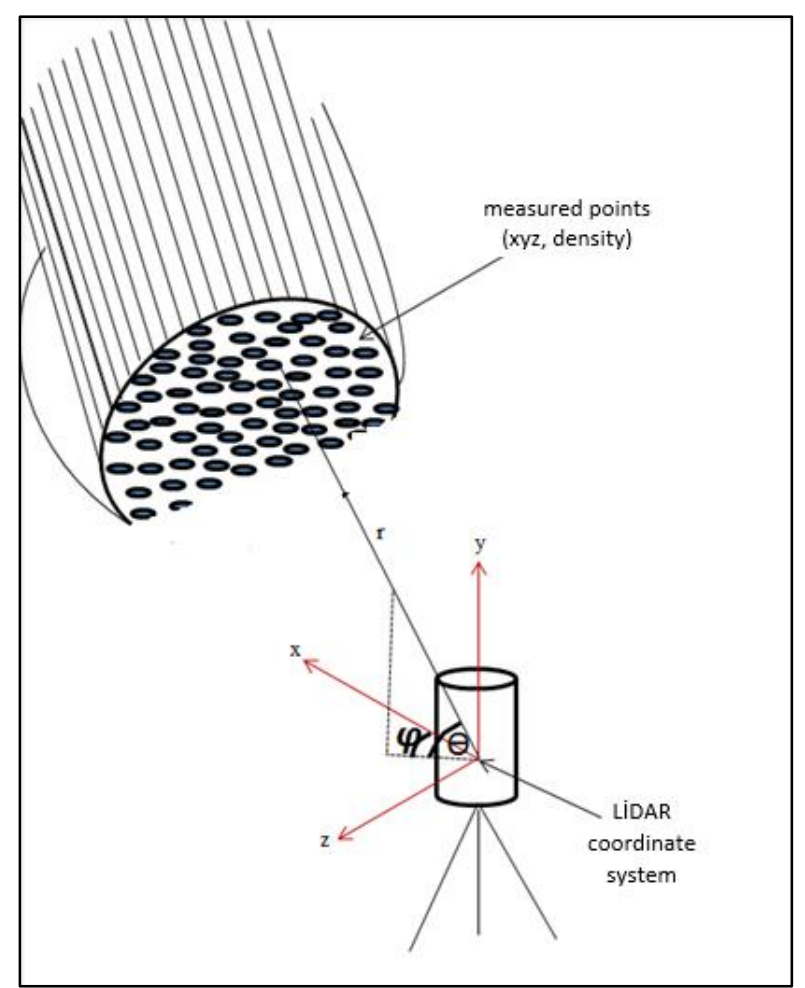

Figure 4. The working principle of the Terrestrial Laser Scanning device

The matrix equation used to convert the polar coordinates obtained from the laser scanner to Cartesian coordinates is given below.

$\mathrm{X}=\left[\begin{array}{c}x j \\ y j \\ z j\end{array}\right]=\left[\begin{array}{c}r j \sin j \cos \theta j \\ r j \sin \theta j \\ r j \cos \varphi j \cos \theta j\end{array}\right]$

$\mathrm{rj}=$ The measured distance of a point $\mathbf{j}$

$\varphi \mathrm{j}=$ The horizontal direction of a point $\mathrm{j}$

$\theta j=$ The vertical angle of a point $\mathbf{j}$

The object to be studied is scanned in both the horizontal and vertical directions using opticalmechanical scanners. The point clusters consisting of millions of data points acquired from the scanned object using intense laser signals are called "point clouds". These point clouds enable creating a 3D model of the investigated object. Since the surface of the studied object can have a very complex shape, the scanning process is conducted from different locations and the obtained data is combined and converted to the geodetic coordinate system (Ingensand, 2006; Gümüş, 2008).

The most important advantage of terrestrial laser scanners is that they allow creating practical and 
accurate 3D models in a fast and precise manner. Objects of different sizes and mixed geometries can be scanned using this technology (Kushwaha et al.2020; Perc, M. and Topolšek, D .; 2020; Wieczorek, T. et al.2018).

The 3D spatial data generated for laser scanning is useful to support a diverse range of mining activities, such as:

- Exploration and resource evaluation

- Design and construction of mine plant and infrastructure

- Determination of ore body, pit and void volumes for mine planning

- $\quad$ Periodic determination of pit, bench, pre-strip and spoil surface volumes for auditing payments to earthworks contractors

- Periodic determination of stockpile volumes for inventory and accounting purposes Environmental planning, monitoring and reporting for the mining operation and the neighboring region.

\section{Terrestrial Laser Scanners Softwares}

Scene: Scene is the most frequently used software for terrestrial laser scanners. This software, which efficiently processes and manages the scanned data, has numerous advantageous features. These features cover recording the scanned data, positioning and automatic object recognition. Scene was especially designed for the FARO Focus3D and Freestyle3D modeling scanners.

3DReshaper: 3DReshaper is a versatile software used in 3D modeling and processing point clouds. Because of its practical use in volume calculation, mesh creation and CAD applications, this software is frequently adopted in 3D modeling applications (URL8).

JRC 3D Reconstructor: Together with the versatility and high resolution of JRC 3D Reconstructor, this software is capable of processing point clouds and images obtained from various sources. Using its LineUp feature, JRC 3D Reconstructor can conduct unoriented scanning and geolocation processes (URL5).

\section{Applications of Terrestrial Laser Scanning in the mining field}

It is generally accepted that the identification and characterisation of discontinuities in discontinuous rock masses is one of the most important aspects in rock mass modelling.

Prevention of negative effects of phenomena occurring in the rock mass is based on detailed recognition of the geological structure (discontinuity, crack, etc.) and mechanical properties of rocks and soils, as well as continuous monitoring of the processes in due course (Bazarnik,2018). In rock mass characterization, examining the properties of the discontinuities is a crucial step toward predicting the mechanical behavior of the rock mass (Bieniawski et al., 1989). In fact, the accurate analysis of these discontinuities (joint bedding planes, fractures, cracks, etc.) is a substantial task in most civil and mining engineering studies. Therefore, it is essential to define the characteristics of each discontinuity set i.e. its orientation, roughness and spacing parameters.

The properties of the discontinuities of a rock mass can be measured using standard methods such as cell mapping or screening line studies (Priest and Hudson, 1981; Priest, 1993). Each of these methods has its own advantages and disadvantages. However, all of these manual field study methods share some common disadvantages (Kemeny and Post, 2003). These drawbacks consist of:

- The emergence of false and inaccurate data because of sampling difficulties (e.g. sampling method selection, human bias, device error, etc.)

- High safety risks. Usually field measurements are carried out at the foot of the existing slopes in quarries, mines and tunnels or along busy highways and railways.

- Direct access to rock surfaces is often difficult or impossible.

Also, traditional manual field survey methods for gathering discontinuity properties are biased, hazardous, difficult, expensive and time-consuming (Slob, 2004).

Thus, adopting TLS technology in combination with an automatic discontinuity analysis has several advantages over the above-mentioned traditional methods:

- TLS technology is less expensive than the traditional methods and provides unbiased, more precise and accurate data on discontinuity orientations.

- Terrestrial Laser scanning can be completed within minutes. This technology minimizes accident risks by providing a controlled safety perimeter of 4 to $800 \mathrm{~m}$ from the study field.

- Laser scanning techniques allow a detailed exploration of rock surfaces. Furthermore, the properties of the discontinuities located in inaccessible areas can be easily obtained.

Investigating the properties of the discontinuities of a rock mass using remote sensing is not a new technique. Analog stereo photogrammetric techniques allowed measuring the orientation of individual discontinuities since the 1960s (Rengers, 1967). Digital images and data processing are also commonly used to determine the properties of discontinuities. Basic photogrammetric techniques combined with pattern recognition allow acquiring 3D models of almost any object (Pollefeys et al., 2000). Applications in the field of rock mechanics have been developed using this technique (Engineering Geology, 2001; Roberts, 2000). When the photogrammetric technique is used, it is still necessary to conduct field measurements at a few control points in the rock mass. In addition, the obtained 3D model requires manual summarization of the discontinuity surfaces to calculate the orientations and reach a suitable 3D model (Feng et al., 2001). In fact, despite the good results offered by this technique, the amount of data points obtained using the photogrammetric method is limited. 
In addition, the manual operation of the total station requires a large amount of time and effort.

An important advantage of 3D laser scanning is its ability to combine rock surface data remotely. Depending on the scanner type, rock surfaces can be reliably and safely scanned from large distances up to even 250 meters. In 3D laser scanning, each scanned point is represented by its coordinate in the $3 \mathrm{D}$ space $\mathrm{X}, \mathrm{Y}$, and $\mathrm{Z}$ relative to the scanner's position) and based on the intensity of the reflected laser beam, a digital dataset illustrated by a dense "point cloud" is obtained. With the use of at least 4 reflectors in the scanned scene, the absolute positions of the scanned points can be obtained and the entire point cloud can be projected onto a local (north-facing) grid in real time.

Today, terrestrial laser scanning technology is widely used in numerous mining engineering applications due to its outstanding advantages. These applications cover the following subjects:

- Determination of discontinuities in open pit and underground mines (Slob et al.2004; Slob et al., 2005; Kemeny et al., 2006; Decker, 2008; Sturzenegger and Stead, 2009; Maerz et al., 2012; Lato et al., 2013; Feke 7 te and Diederichs, 2013, Deliormanlı et al., 2014),

- Calculating shotcrete thickness in tunnels, determining possible deformation measurements in tunnels, automating lighting fixtures in tunnels (Chun-Lei et al., 2019; Puente et al., 2014; Delaloye and Diederichs, 2011; Fekete et al., 2009),

- Conducting deformation measurements to control rock falls and landslides (Bauer et al., 2005; Aksoy \& Ercanoglu, 2006; Özdoğan et al., 2018; Teza et al., 2008; Abellán et al., 2008; Salvini et al., 2013),

- Designing 3D slope and bench geometry (Feng \& Röshoff, 2004; Yanalak, 2005; Oparin et al., 2007),

- Conducting different volume calculations (Yanalak and Baykal, 2003; Yakar et al., 2008),

- Analyzing blasting results (Engin and Maerz., 2016).

Sturzenegger \& Stead (2009) used a laser scanner to conduct a 3D modeling analysis of an open pit and characterize the identified discontinuity sets (Figure 5). Examples of models obtained using the TLS technology for different mining engineering applications are presented below.

Maerz et al. (2012) conducted a LiDAR scan to create a point cloud of a Missouri ignimbrite rock cut rock and painted each point by its corresponding optical color (Figure 6).

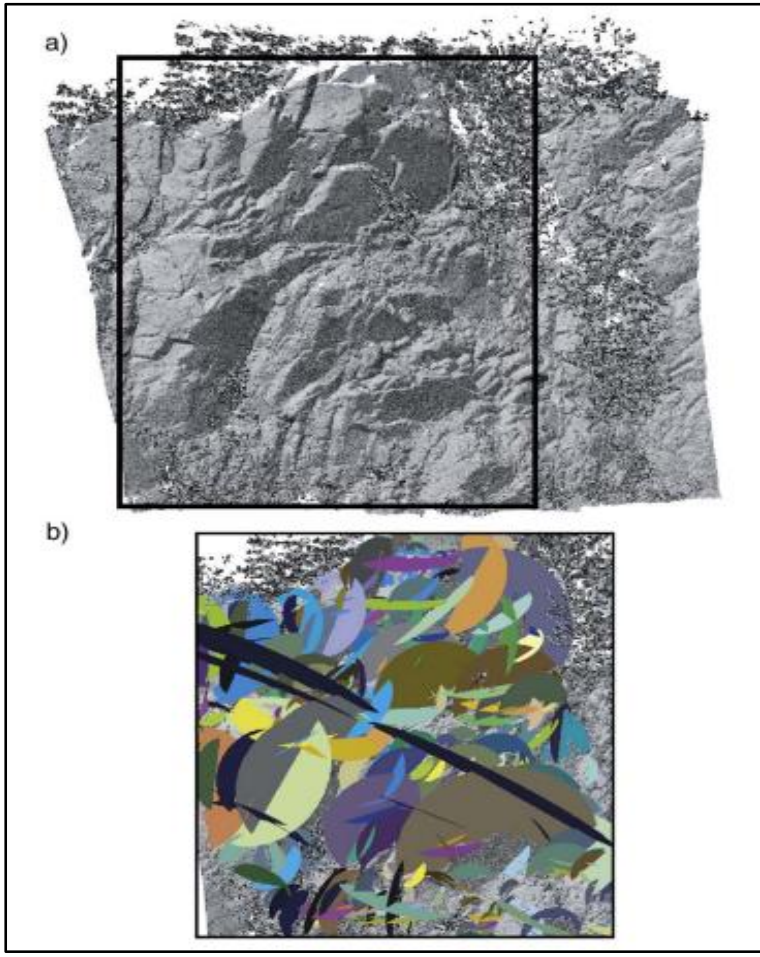

Figure 5. Discontinuity characterization in 3D models. (a) Laser scanner point cloud with a selected sampling window, (b) circles and traces placed on recognizable discontinuity surfaces (Sturzenegger \& Stead, 2009).
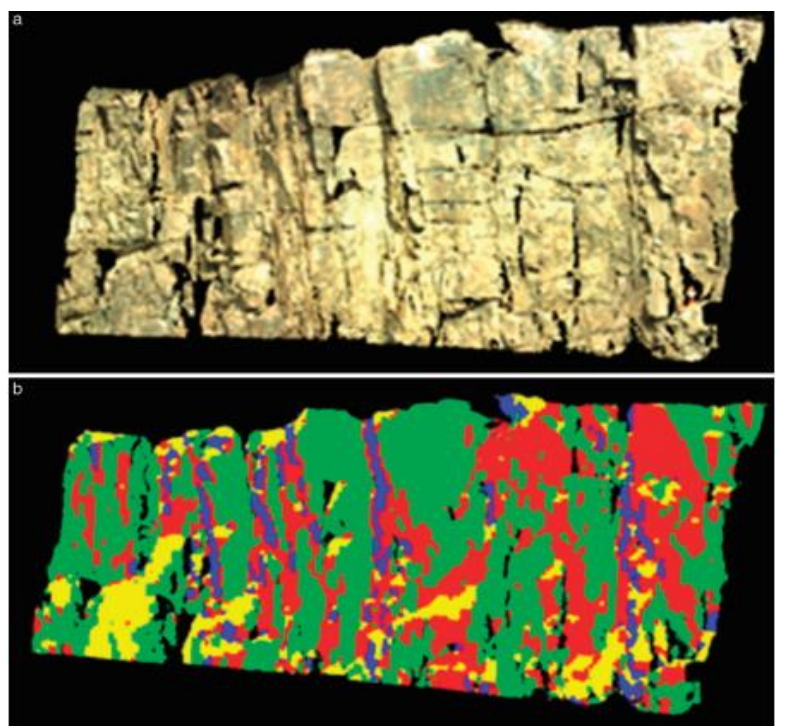

Figure 6. (A) LiDAR scan of a Missouri ignimbrite rock cut. This point cloud was generated with a Leica ScanStation II, which incorporates optical imaging and allows each point in the point cloud to be painted by its corresponding optical color. (B) Automatic identification of discontinuity orientations; the different colors are assigned to discontinuities of similar orientations based on cluster analysis. Green color represents mean orientation of $88 / 186$, blue represents mean orientation of $89 / 277$, yellow represents mean orientation of $37 / 338$, and red represents mean orientation of $82 / 203$. (Maerz et al., 2012). 
Fekete et al. (2009) used laser scanners to create a 3D model the opening of the Sandvika tunnel near Oslo, Norway. The results of the conducted TLS measurement campaign enabled specifying the necessary thickness of the shotcrete, defining the properties of the support quality control and predicting the leakage behind the lining. In addition, valuable information on the orientation, spacing and roughness of the joint sets, structurally controlled overbreak geometry and identification of discontinuities visible as lineations in successive rounds were obtained using this technology.

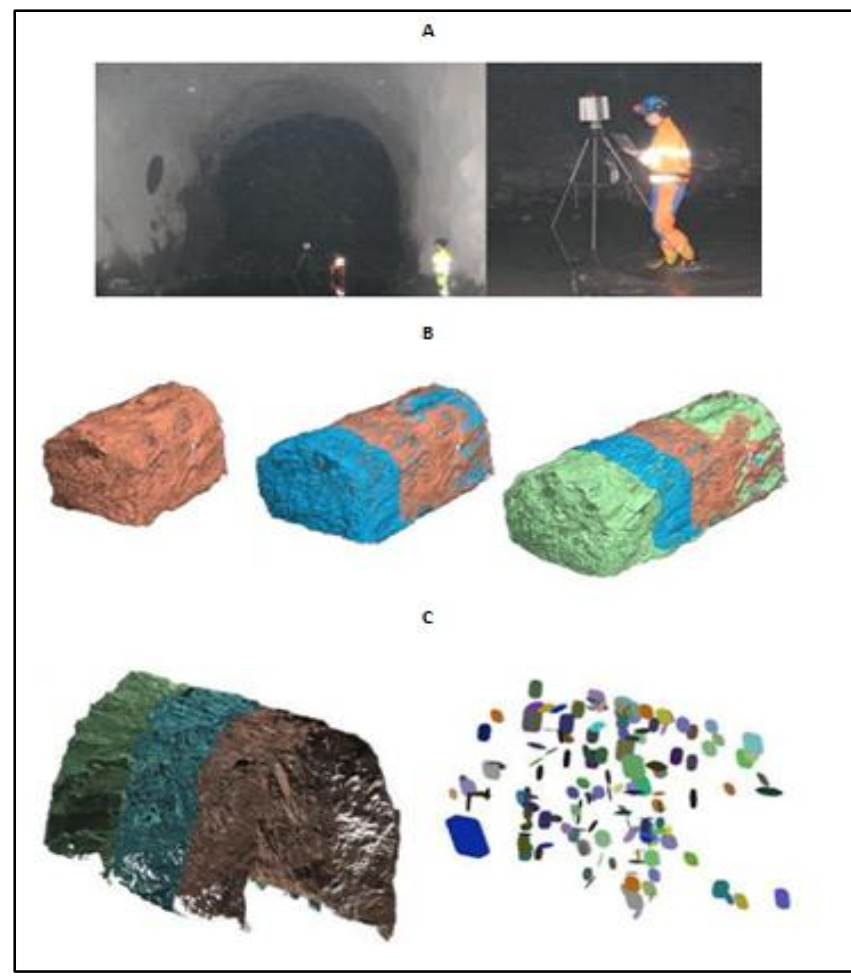

Figure 7. (A) Lidar tripod set up at $10 \mathrm{~m}$ diameter Sandvika tunnel near Oslo, Norway. (B) Alignment of three $5 \mathrm{~m}$ rounds of an advancing drill and blast tunnel, meshed model, Sandvika. (C) Bare rock polygonal model (left) and 158 identified joint surfaces (right) from three 5 m rounds, Sandvika site (Fekete et al., 2009).

Abellán et al. (2008) conducted a study on the rockfall at Vall de Núria located in the Eastern Pyrenees using a long-range terrestrial laser scanner. The authors performed 8 scans at 3 different stations to obtain the coordinated of approximately 4 million points. The acquired data allowed creating a highly accurate Digital Elevation Model (DEM) and reconstructing the joint geometry in the studied area. The paper also attempted to model the geometry and volume of the source area in recent rockfalls.

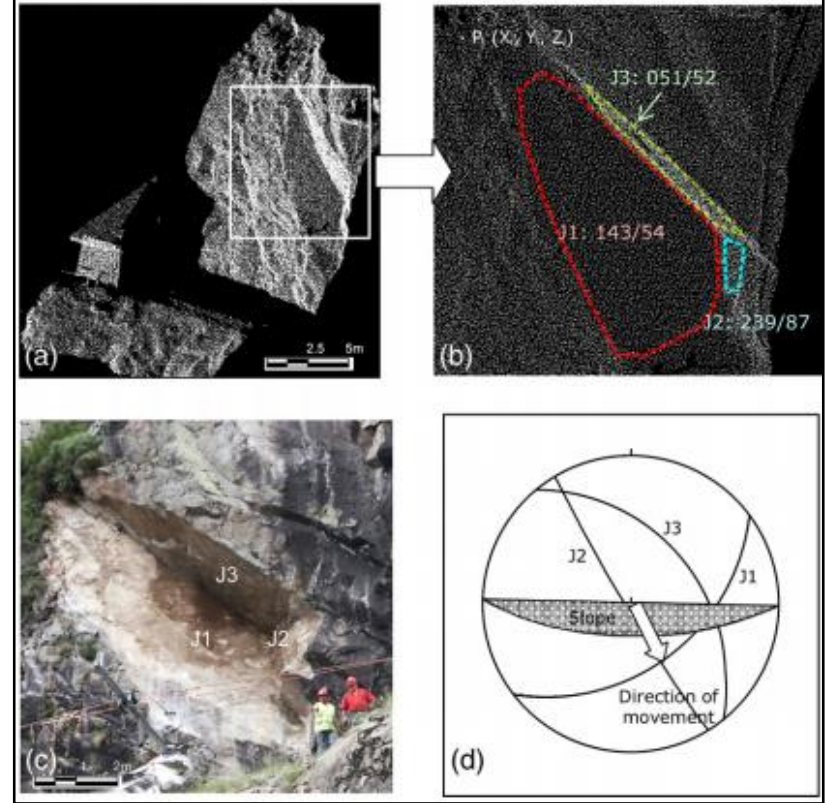

Figure 8. (a) 3-dimensional point cloud of the detachment area in c. The selected area is magnified in b. (b) Geometry model of the 3D point cloud of the joints: J1, J2, and J3. (c) Photograph of the same area. (d) Stereographic projection of the joints: J1, J2, J3 and the wedge between the direction of movement J1 and J2 (Abellán et al., 2008).

Oparin et al., (2007) developed a 3D digital model to describe the hierarchical structure of geoblocks at a limestone deposit. The ready-made 3D digital model of the open-pit side surface developed based on the surface laser scanning allowed linear measurements of the rock mass geoblocks with no in-situ linear and angular measurements. The obtained digital model was also used to determine the properties of objects for lay-outs, crosssections and profiles and to evaluate metric (linear and angular) areas and volumes.

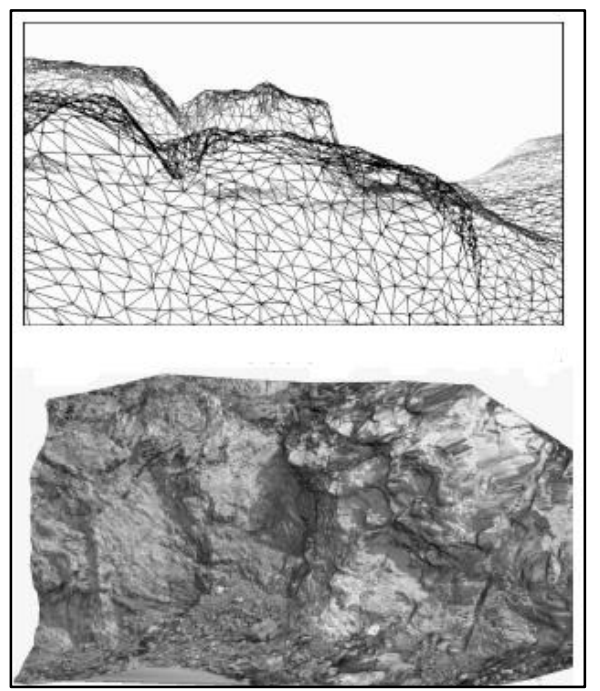

Figure 9. Fragment of the 3D digital model of the vertical pit side surface, developed by the surface laser scanner with a precision of $15 \mathrm{~mm}$ (Oparin et al., 2007) 
Engin \& Maerz (2016) developed a method that enables determining the particle size distribution resulting from blasting operations by evaluating the point cloud data obtained from terrestrial laser scanners. The particle size distribution of a laboratory-scale aggregate mixture and a pile obtained from a stone quarry with an already known size distribution were firstly determined using TLS technology. When the obtained point clouds were compared to the results of the sieve analysis conducted on these two samples, it was found that TLS technology provides highly accurate results. This paper demonstrated the efficiency of this Terrestrial Laser Scanning in analyzing the particle size distribution of the blasted materials.

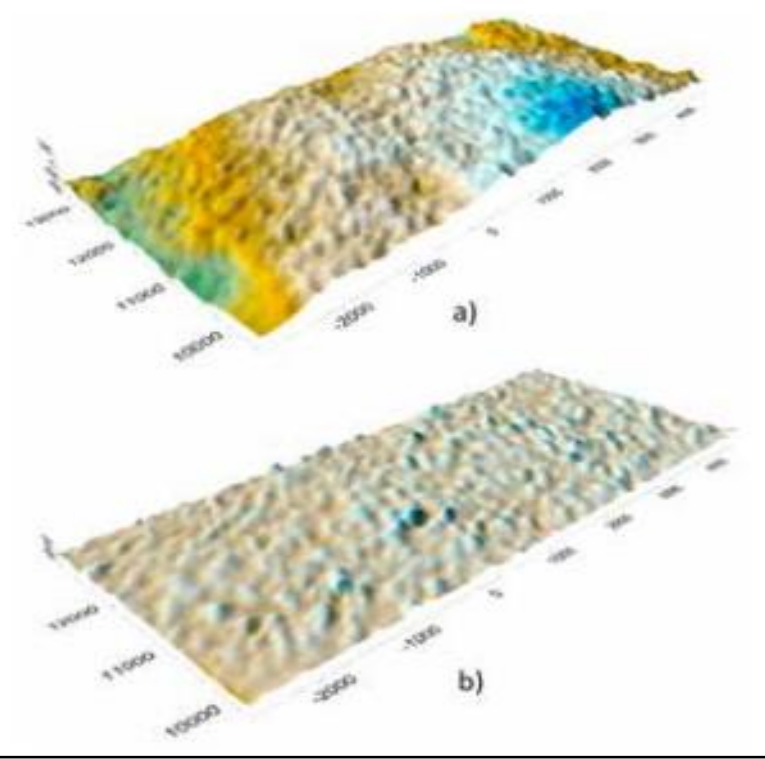

Şekil 10. (a) Original 3D model of the crushed aggregate pile in the studied quarry (b) A view of the same model after correction (Engin \& Maerz, 2016).

\section{CONCLUSION}

This study reviews Terrestrial Laser Scanning technology (TLS), its measurement and working principle, its advantages and the main softwares that can be used to model the results obtained from this technology. Numerous studies highlighted that geodesic and photogrammetry methods are less effective than the TLS method in terms of accuracy, speed and efficiency in conducting the necessary calculations during the measurement process which explains the increasingly higher popularity of this technology.

Numerous softwares can be used to interpret Terrestrial laser scanning data for the objective of modeling objects of different sizes and geometries, conducting numerous calculations and for reconstructing purposes.

Today, Terrestrial Laser Scanning technology is widely used in numerous mining engineering applications due to its outstanding advantages. These applications cover the determination of discontinuities in quarries and mines, deformation measurements, evaluating and monitoring blasting results, investigating rock falls and landslides and 3D design of slope and bench geometry.

Nowadays, terrestrial laser scanning technology became an efficient tool to most engineering applications. On account of its reliability, accuracy and efficiency, Terrestrial Laser Scanning technology has become an efficient tool in numerous applications. The usage areas of this technique keep expanding as it has been proven to be a more advantageous than the traditional methods in terms of operability, reliability and time and cost efficiency.

\section{REFERENCES}

Abellán A, Vilaplana J M \& Martínez J (2008). Application of a long-range terrestrial laser scanner to a detailed rockfall study at Vall de Núria (Eastern pyrenees, Spain), Eng Geol 88, 136-148.

Aksoy H \& Ercanoglu M (2006). Determination of the rockfall source in an urban settle-ment area by using a rule-based fuzzy evaluation. Natural Hazards and Earth System (6), 941-954.

Bauer A, Paar G \& Kaltenböck A (2005). Mass movement monitoring using terrestrial laser scanner for rock fall management. In: Proc first international symposium on geo-information for disaster management, 393406.

Bazarnik M (2018) Slope stability monitoring in open pit mines using $3 D$ terrestrial laser scanning, 4th International Conference on Applied Geophysics, E3S Web of Conferences 66, 01020

Bieniawski Z T (1989). Engineering Rock Mass Classification. John Wiley and Sons, New York, 1989.

Boehler W \& Marbs A (2002). 3d Scanning instruments. Proceeding of the CIPA WG6 International Workshop on Scanning for Cultural Heritage Recording.

Chun-Lei, Luo, et al., (2019). Intelligent Detection for Tunnel Shotcrete Spray Using Deep Learning and LiDAR. IEEE Access (8), 1755-1766.

Decker J (2008). Laser scanning techniques in Devil's Slide tunnels. In: Proceedings of the 42nd US rock mechanics symposium, San Francisco.

Delaloye D, Hutchinson J \& Diederichs M (2011). Accuracy issues associated with Lidar scanning for tunnel deformation monitoring. Proceedings of the 2011 Pan-AM CGS Geotechnical Conference.

Deliormanlı A H, Maerz N \& Otoo J N A (2014). Using terrestrial 3D laser scanning and optical methods to determine orientations of discontinuities at a granite quarry, International Journal of Rock Mechanics and Mining Sciences, (66), 41-48.

Engin İ C \& Maerz N (2016). Patlatma Sonuçlarının Analizinde Yersel Lazer Tarayıcıların (LiDAR) Kullanımı. Bilimsel Madencilik Dergisi, 55(1), 35-44.

Fasching A, Gaich A \& Schubert W (2001). Data acquisition in Engineering Geology. An Improvement of Acquisition Methods for Geotechnical Rock Mass Parameters, Felsbau, 19, (5), 93-101.

Fekete S \& Diederichs M (2013). Integration of threedimensional laser scanning with discontinuum modelling for stability analysis of tunnels in blocky rock masses. International Journal of Rock Mechanics \& Mining Sciences, (57), 11-23. 
Fekete S, Diederichs M \& Lato M (2009). Geotechnical application of lidar scanning in tunnelling. 3rd CANUS Rock Mechanics Symposium, Toronto. 1-12.

Feng Q, Sjogren P, Stephansson O \& L Jing (2001). Measuring Fracture Orientation at Exposed Rock Faces by Using a Non-Reflector Total Station. Engineering Geology, (59), 133-146.

Feng Q H \& Röshoff K (2004). In-situ mapping and documentation of rock faces using full-coverage 3D laser scanning techniques. International Journal of Rock Mechanics and Mining, (41), 379.

Fröhlich C \& Mettenleiter M (2004). Terrestrial Laser Scanning - New Perspectives in 3D Surveying, In International Archives of the Photogrammetry. Remote Sensing and Spatial Information Sciences. Cilt. XXXVI-8/W20.

Gümüș K (2008) Yersel Lazer Tarayıcılar ve Konum Doğruluklarının Araştırılması, Yüksek Lisans Tezi, Yıldız Teknik Üniversitesi Fen Bilimleri Enstitüsü, İstanbul, $134 \mathrm{~s}$. (in Turkish).

Ingensand $H$ (2006). Methodological aspects in terrestrial laser-scanning technology. 3rd IAG / 12th FIG Symposium, Baden.

Karasaka L \& Beg A A R (2021). Yersel Lazer Tarama Yöntemi ile Farklı Geometrik Yapıdaki Özelliklerin Modellenmesi. Geomatik, 6(1), 54-60.

Karşıdağ G (2011). Yersel lazer tarama ölçmelerinde doğruluk analizi. İstanbul Teknik Üniversitesi, Yüksek Lisans Tezi. İstanbul. (in Turkish).

Kemeny J \& Post R (2003). Estimating three-dimensional rock discontinuity orientation from digital images of fracture traces. Computers and Geosciences vol. 29, pp. 65-77.

Kemeny J \& Post R (2003). Estimating ThreeDimensional Rock Discontinuity Orientation from Digital Images of Fracture Traces, Computers and Geosciences, Vol. 29, pp. 65-77.

Kemeny J, Turner K \& Norton B (2006). LiDAR for Rock Mass Characterization: hardware, software, accuracy, and best practices. Laser and Photogrammetric Methods for Rock Face Characterization workshop, Golden Colorado, 49-62.

Kraus K (2004). Photogrammetrie Band 1, Geometrische Informationen aus Photographien und Laserscanneraufnahmen. Walter de Gruyter Verlag, Berlin, 7. Auflage.

Kushwaha S K P, Dayal K R, Raghavendra S, Pande H, Tiwari P S, Agrawal S \& Srivastava S K (2020). 3D Digital Documentation of a Cultural Heritage Site Using Terrestrial Laser Scanner-A Case Study. In Applications of Geomatics in Civil Engineering (pp. 49-58). Springer, Singapore.

Lato M, Kemeny J, Harrap R M Bevan G (2013). Rock bench: Establishing a common repository and standards for assessing rockmass characteristics using LiDAR and photogrammetry. Computers \& Geosciences 50, 106-114.

Maerz N H, Youssef A M, Otoo J N, Kassebaum T J \& Duan $Y$ (2012). A simple method for measuring discontinuity orientations from terrestrial LiDAR images. Sub. to J. of Environmental and Engineering Geoscience.
Oparin V N, Seredovich V A, Yushkin V F, Ivanov A V, Prokop'eva S A (2007). Application of laser scanning for developing a 3D digital model of an open-pit side surface. Journal of Mining Science 43(5), 545-554.

Özdoğan M V (2015). Madencilik Faaliyetleri Sonucu Oluşan Yüzey Hareketlerinin Yeni Teknolojiler İle Belirlenmesi.. Dokuz Eylül Üniversitesi Fen Bilimleri Enstitüsü, Doktora Tezi, 183s, İzmir. (in Turkish).

Perc M N \& Topolšek D (2020). Using the scanners and drone for comparison of point cloud accuracy at traffic accident analysis. Accident Analysis \& Prevention, 135, 105391.

Pollefeys M, Koch R, Vergauwen M \& Van Gool L (2000). Automated Reconstruction of 3D Scenes from Sequences of Images, ISPRS Journal ofPhotogrammetry \& Remote Sensing, 55 (4), 251267.

Priest S D \& Hudson J A (1981). Estimation of Discontinuity Spacing and Trace Length Using Scanline Surveys, International Journal of Rock Mechanics and Mining Sciences \& Geomechanics, Vol. 18, pp. 183-197.

Priest S D (1993). Discontinuity Analysis for Rock Engineering. Chapman \& Hall, p. 473, London.

Puente, Iván, et al. (2014). Automatic detection of road tunnel luminaires using a mobile LiDAR system. Measurement 47, 569-575.

Rengers N (1967). Terrestrial Photogrammetry: A Valuable Tool for Engineering Geological Purposes, Rock Mechanics and Engineering Geology, Vol. V/2-3, pp. 150-154.

Roberts G \& Poropat G (2000). High wall Joint Mapping in 3D at the Moura Mine Using SIROJOINT, Coal and Mining, The New Millennium, Rockhampton, Australia.

Slob S, Hack R, Knapen B \& Kemeny J (2005). A method for automated discontinuity analysis of rock slopes with 3D laser scanning. In: Proceedings of the 84th annual meeting of Transportation Research Board, 16 pp Washington.

Slob S, Hack R, Van Knapen B \& Kemeny J (2004). Automated identification and characterisation of discontinuity sets in outcropping rock masses using 3D terrestrial laser scan survey techniques, In Proceedings of the ISRM Regional Symposium EUROCK 2004 \& 53rd Geomechanics Colloquy, 439443, Salzburg.

Sturzenegger M \& Stead D (2009). Close-range terrestrial digital photogrammetry and terrestrial laser scanning for discontinuity characterization on rock cuts, Engineering Geology 106, 163-182.

Teza G, Pesci A, Genevois R \& Galgaro A (2008). Characterization of landslide ground surface kinematics from terrestrial laser scanning and strain field computation, Geomorphology 97, 424-437.

URL5:http://www.gexcel.homeip.net/Reconstructor/R_ Manual/R_Manual_EN.pdf.

URL8:http://www.3dreshaper.com/images/brochures/ BeginnersGuide_EN.pdf.

Wieczorek T, Przyłucki R, Lisok J \& Smagór A (2018). Analysis of the Accuracy of Crime Scene Mapping Using 3D Laser Scanners. In International Workshop on Modeling Social Media, pp. 406-415. 
Wieczorek T, Przyłucki R, Lisok J, Smagór A (2018). Analysis of the Accuracy of Crime Scene Mapping Using 3D Laser Scanners. In International Workshop on Modeling Social Media, pp. 406-415.

Yakar M, Yılmaz H M, Mutluoğlu Ö (2008). Lazer Tarama Teknolojisi ve Fotogrametrik Yöntem ile Hacim Hesabı. TÜBİTAK, Proje No: 105M179, 90s.
Yanalak M \& Baykal O (2003). Digital Elevation Model Based Volume Calculations Using Topographical Data, Journal of Surveying Engineering 129 (2), 56-64.

Yanalak M (2005). Computing Pit Excavation Volume. Journal of Surveying Engineering 131(1), 15-19.

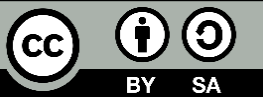

(C) Author(s) 2021.

This work is distributed under https://creativecommons.org/licenses/by-sa/4.0/ 